\title{
LA DIFICULTAD PROBATORIA EN EL PROCESO LABORAL EN EL CHACO, ARGENTINA
}

THE PROBATORY DIFFICULTY IN THE JUDICIAL PROCESS OF CHACO, ARGENTINA

\section{JORGE GUSTAVO DAHLGREN}

Facultad de Ciencias Económicas

Universidad Nacional del Nordeste

ARGENTINA

La ciencia es un magnífico mobiliario para el piso superior de un hombre, siempre y cuando su sentido común esté en la planta baja. Oliver Wendell Holmes 


\section{RESUMEN}

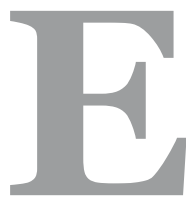

l presente trabajo tiene la finalidad de conocer algunas características especiales de la valoración de la prueba de difícil producción e interpretación dentro del proceso laboral, dando especial atención a precedentes judiciales de la Provincia del Chaco y en tal sentido se acudió a pautas, utilizadas tanto por la jurisprudencia como la doctrina, local y nacional, destacables y relevantes para la formación de criterio para la interpretación de normas adjetivas que fueron. En este ámbito imperan principios rectores distintos a otras ramas del derecho, con motivo de dar importancia a protección de supuesto trabajador demandado y la necesidad de dar trascendencia a la realidad subyacente del vínculo laboral, que en variadas ocasiones se encuentra disimulado bajo el disfraz de otras figuras jurídicas.

Básicamente la legislación laboral de fondo tiene prevista las presunciones básicas para la determinación del vínculo laboral, sin embargo cuando nos encontramos en presencia de complejidades probatorias, podemos advertir la existencia las presunciones específicas para la demostración de determinados hechos tales como el accidente de trabajo o enfermedades profesionales, algunas comprobaciones de vínculos laborales disimulados, entre otros. No encontrándose expresamente previstas estas presunciones específicas en la ley, resulta necesario echar luz sobre la cuestión, acudiendo al análisis de distintos precedentes jurisprudenciales, de acuerdo a la valoración de los diversos medios probatorios, tal como se expone a continuación.

Palabras Clave: dificultades probatorias, proceso laboral.

\section{ABSTRACT}

The present work has the purpose of knowing some special characteristics of the evaluation of the test of difficult production and interpretation within the labor process, giving special attention to judicial precedents of the Province of Chaco and in that sense it was used to guidelines, used both by The jurisprudence as the doctrine, local and national, remarkable and relevant for the formation of criterion for the interpretation of adjective norms that were. In this area prevailing guiding principles different from other branches of law, in order to give importance to the protection of supposed worker Defendant and the need to give importance to the underlying reality of the employment relationship, which on several occasions is hidden under the guise of other legal figures. Basically the basic labor legislation provides for the basic presumptions for determining the employment relationship, however when we are in the presence of probationary complexities, we can notice the existence of specific presumptions for the demonstration of certain facts such as work accidents or diseases Professionals, some checks of hidden labor links, 
among others. Not being expressly foreseen these specific presumptions in the law, it is necessary to shed light on the question, going to the analysis of different jurisprudential precedents, according to the valuation of the various evidentiary means, as set forth below.

Keywords: difficulties probationary, labor process.

\section{INTRODUCCIÓN}

El presente trabajo de investigación se refiere a las dificultades probatorias existentes en el proceso laboral del Chaco, pero acudiendo a antecedentes legislativos y precedentes jurisprudenciales de otras jurisdicciones de nuestro país, para integrar algunas cuestiones interpretativas planteadas.

Esta actividad comienza con el ofrecimiento de las pruebas, de acuerdo al hecho que se pretenda acreditar, para luego continuar su curso de su producción de acuerdo al medio elegido, requiriéndose el esfuerzo del oferente para logar su efectividad, caso contrario podría tener por decaído el ofrecimiento debido a su desidia.

Su alcance, depende de la estrategia planteada, tanto en base al diseño del reclamo como al grado de tolerancia adoptado por la parte demandada en oportunidad de efectuar la negación o aceptación de los hechos y de este modo, queda demarcado, el limite fáctico a ser considerado por el juzgador al momento de resolver la cuestión debatida.

Es importante lograr agilidad en la capacidad de selección de los medios probatorios, para proveer medios adecuados y conducentes para la dilucidación de la verdad real de los hechos a efecto de alcanzar un adecuado orden procesal y beneficio de la celeridad.

\section{RÉGIMEN JURÍDICO DE LA PRUEBA EN EL PROCEDIMIENTO LABORAL}

La producción de la prueba debe efectuarse de acuerdo a los medios previstos por la ley procesal o también por los que el Juez disponga y para el supuesto caso de que se ofreciere algún otro medio probatorio "idóneo y pertinente no previsto de modo expreso en este Código, el Juez establecerá la manera de diligenciarlo, empleando el procedimiento determinado para otras pruebas que fuere analógicamente aplicable". ${ }^{1}$

Tanto las leyes de fondo y de forma se refieren a la prueba, siendo útil señalar que la nueva legislación civil y comercial, establece que los contratos pueden ser probados por los medios

${ }^{1}$ Código Procesal Laboral de la Provincia del Chaco (Ley N 7.434) Art. 190 II y III 
aptos para llegar a una razonable convicción, según las reglas de la sana crítica y con arreglo a las leyes procesales. ${ }^{2}$

Concretamente la ley adjetiva laboral de la Provincia del Chaco, dedica al Título VIII compuesto de seis capítulos a los distintos medios de prueba, previéndose la misma regla de valoración de la prueba o sea de acuerdo las reglas de la sana crítica racional. ${ }^{3}$

Los medios referidos consisten en la regulación de prueba documental, testimonial, informativa, pericial e inspección judicial, entre otras ${ }^{4}$, básicamente y del mismo modo previsto por los ordenamientos adjetivos en lo civil y comercial tanto de la Nación ${ }^{5}$ como de la Provincia. ${ }^{6}$

Conforme a ello, en principio, cada parte debe probar los hechos que invoca en su apoyo, haciendo la salvedad que nuevo proceso laboral no legisló la prueba confesional, conocida también como absolución de posiciones.

Cabe puntualizar que: "el objeto de la prueba solo puede estar constituido por los hechos invocados por las partes que hayan sido controvertidos... esenciales y conducentes para la resolución del conflicto" (Pirolo. M. A., 2011, p. 209).

Consecuentemente no resultan admisibles aquellas pruebas que fueren manifiestamente improcedentes, superfluas o meramente dilatorias, encontrándose el juez facultado para disponer su denegación por medio de resolución fundada, pero sin embargo es posible apelar tal decisión. ${ }^{7}$

Ahora bien, se entiende que la prueba es atendible cuando tiene entidad suficiente para alcanzar el convencimiento del juez, sobre la verdad de los hechos, cuestión que es evaluada por el Juez generalmente al momento de dirigir el desarrollo de la audiencia de vista de causa, a fin de lograr su adecuada depuración.

\section{APRECIACIÓN DE LA PRUEBA}

El juzgador no tiene la obligación de valorar todas y cada una de las pruebas producidas, sino las consideradas conducentes y aptas para resolver la cuestión, siempre dentro de los limites marcado por la congruencia.

Cuenta con facultades para jerarquizar y seleccionar los medios probatorios, prefiriendo algunos y descartando otros, lógicamente de acuerdo al grado de credibilidad que le merezcan, sin que ello configure un apartamiento a los principios de valoración probatoria. ${ }^{8}$

\footnotetext{
${ }^{2}$ Código Civil y Comercial de la Nación (Ley N²6.994), art. 1019.

${ }^{3}$ Ley $\mathrm{N}^{\circ} 7434$, art. 194

${ }^{4}$ Ley $\mathrm{N}^{\circ} 7434$, arts. 212 a 274

${ }^{5}$ Código Procesal Civil y Comercial de la Nación (Ley N²2.434)

${ }^{6}$ Código Procesal Civil y Comercial de la Provincia del Chaco (Ley N ${ }^{\circ} 7.950$ )

${ }^{7}$ Ley $\mathrm{N}^{\circ} 7434$, artículo 192

${ }^{8}$ Cámara de Apelaciones del Trabajo, Resistencia, Sala $2^{\circ}$ (24/04/01) "Monfardini Félix R. c/ Palmaz Rudeneldo R. y/o Juan Cincotta y/o Quien resulte responsable s/ Despido, etc.", Expte. $N^{\circ}$ 067/01. Sentencia $N^{\circ} 27$. Tribunal de Orígen: Juzgado del Trabajo $\mathrm{N}^{\circ} 2$, bajo $\mathrm{N}^{\circ} 7.837 / 96$.
} 
Como ya se adelantó, nuestra legislación adjetiva laboral, adoptó el principio de la sana crítica racional $^{9}$, sin embargo y a título ilustrativo se menciona la existencia de otros sistemas, a saber:

a) Prueba tasada: Sistema adoptado por los antiguos ordenamientos, donde el legislador señala al juez el valor que le debe asignar a cada medio de prueba, sin perjuicio del convencimiento del magistrado;

b) Libre convicción: Se lleva a cabo de conformidad a la conciencia del Juez y se encuentra vigente en las legislaciones ajenas a la influencia hispánica, en países tales como Alemania, Brasil, Italia y el Vaticano, entre otros.

c) Sana crítica racional: Si bien se encuentra nombrado por la legislación adjetiva, el mismo no se encuentra definido conceptualmente, siendo necesario entonces indicar que consiste en un proceso intelectivo y lógico de razonamiento humano llevado a cabo con sinceridad y buena fe, con respecto a los elementos producidos en el expediente judicial.

Se trata de una regla del entendimiento humano, razonamiento lógico y objetivo relacionado con la experiencia, sentido común, sabiduría, conocimientos científicos psicología, coherencia, sentido común, certeza moral y recto entendimiento al que toda persona en su sano juicio ajustaría sus conviccione ${ }^{10}$ y que inciden sobre el criterio personal de los jueces, aproximando el conocimiento al grado de certeza.

Constituye de una categoría intermedia entre sistemas opuestos, que sin excesivas abstracciones evita caer en los excesos de la libre convicción pero sin alcanzar la rigidez, ni la incertidumbre que presenta la prueba tasada, aportando un medio de interpretación flexible para enfrentar el riesgos de encontrarnos con la imposibilidad de resolver cuestiones complejas.

Un aspecto esencial de esta regla está dado por la denominada "higiene mental", que pretende evitar todo tipo de interpretación arbitraria, absurda e irracional, despejando las influencias negativas de las cargas emocionales al momento de resolver.

Si bien la valoración de la prueba debe llevarse a cabo en base a estos lineamentos, debemos agregar que, dentro de proceso laboral, inciden de modo determinante, principios y presunciones que operan a favor de los intereses del trabajador, aspecto que lo distingue de otras disciplinas, por su carácter netamente protectorio.

\section{LAS PRESUNCIONES GENÉRICAS PARA LA ACREDITACIÓN DEL VÍNCULO}

De modo genérico diremos que, en todo proceso judicial, quien alega un hecho debe probarlo, sin embargo el laboral, acude a ficciones conocidas como presunciones legales que

\footnotetext{
${ }^{9}$ Ley $\mathrm{N}^{\circ} 7.434$, art. 194.

${ }^{10}$ Suprema Corte de Justicia de Mendoza, Sala $2^{\circ}$ (29/08/95) "Inca S.A. Cía. de Seguros en autos: “Casado Serafín c/ Electricidad Oeste y otros s/ Ordinario", Jueces: Aguilar - Nanclares - Salvini.
} 
consiste en la aplicación de normas procesales protectorias para encausar la protección del trabajador, en atención a su posición hiposuficiente dentro de la relación procesal, con la clara intención de eliminar desigualdades, facilitar el acceso a la jurisdicción y el agilizar tránsito del reclamo judicial del trabajador. ${ }^{11}$

Concretamente, la ley adjetiva chaqueña, siguiendo los preceptos de la ley de fondo, establece que "cada parte probar los presupuestos de hecho de la posición que sustenta en el supuesto de que fuera controvertida, sin perjuicio de las presunciones establecidas a favor del trabajador tanto en las leyes de fondo como de forma, estatutos especiales, convenios colectivos de trabajo o normas de policía laboral". ${ }^{12}$

Con respecto a las presunciones establecidas por la legislación laboral, calificada doctrina ha entendido que: "representa un caso de inversión de la carga de la prueba, porque favorece a quien la invoca y pone a cargo de la otra parte la prueba en contrario. Pero la condición sine qua non para que surja la presunción es que los indicios se hallen constatados, lo que significa que al que alega la presunción de un hecho, corresponde la carga de la prueba de los indicios que han de servir de soporte al juez para su razonamiento" (Vitantonio N., T II, p. 115).

En variadas circunstancias, la parte demandada suele ocultar la relación laboral bajo las formas de un contrato de otra naturaleza, generalmente del ámbito civil, acudiendo a diversos artilugios para disimular su existencia (Ensink, J., 1976, p.146).

La parte demandada, por lo general el empleador, suele plantear como defensa la inexistencia de la relación laboral y ante tal supuesto, quien reclama la existencia del vínculo comúnmente el pretenso trabajador, necesita activar las presunciones legales, para verse beneficiado con la misma. ${ }^{13}$

En razón de ello, como primera medida probatoria, resulta de vital importancia la acreditación del vínculo laboral a través a través de cualquier medio, siendo el más generalizado y conocido la prueba testimonial. ${ }^{14}$

De este modo, surge un punto de inflexión dentro del proceso laboral, donde se nace la protección procesal para el trabajador, desplazándose la carga probatoria (Vázquez Vialard, 1996, págs. 466 y 467).

Es a partir de ese momento, la ley procesal pone en cabeza del empleador demandado la obligación de aportar elementos suficientes para oponerse a las pretensiones el trabajador.

Pasa a tener el deber de desvirtuar las aseveraciones expuestas en el escrito de demanda, debiendo acreditar por ejemplo cual fue fecha de ingreso, el monto del salario, las condiciones y ambiente laboral, entre otras cuestiones trascendentes.

Esta ficción constituye un modo de dar respuesta a la natural dificultad que tiene el trabajador de reunir los elementos probatorios que, naturalmente deben encontrarse dentro del

\footnotetext{
${ }^{11}$ Ley de Contrato de Trabajo (Ley $N^{\circ} 20.744$ ), arts. 23 y 50

${ }^{12}$ Ley $\mathrm{N}^{\circ} 7.434$, art. 193

${ }^{13}$ Ley $\mathrm{N}^{\circ} 20.744$, art. 23

${ }^{14}$ Ley $\mathrm{N}^{\circ} 7.434$, art.731
} 
establecimiento del empleador, sobre quien pesa la obligación de llevar los libros y registración con las formalidades de ley. ${ }^{15}$

\section{DIFICULTAD PROBATORIA Y LAS PRESUNCIONES ESPECÍFICAS}

Esta cuestión, presenta un supuesto más específico, con un elevado grado de dificultad, porque nos encontramos con una verdadera ausencia de prueba categórica y directa, para alcanzar un grado convicción compatible con el de certeza moral.

Un ejemplo claro es la falta de testigos presenciales, para la acreditación de algún hecho relevante, generalmente distinto a la simple relación laboral, como resulta ser el accidente de trabajo o enfermedad profesional, entre otras cuestiones.

Si bien se trata de una cuestión compleja, no deber ser entendida como una situación de orfandad probatoria, que imposibilite llegar a un juicio de valor para lograr una solución adecuada, motivo por el cual resulta necesario bajar el límite del rigor normalmente empleados en la generalidad de los casos (Morello, 2003, p. 178).

Ante la presencia de un hecho de difícil acreditación, no es posible exigir su demostración de modo estricto, como por ejemplo la existencia de la mecánica exacta de un siniestro laboral.

Es posible entonces acudir por la vía de las presunciones, que constituye un camino de acceso indirecto y naturalmente más débil, a través de la constatación de varios factores tales como los indicios relevantes, valoración de la conducta de las partes en la producción de la prueba, e investigación de los hechos expuestos bajo la óptica de los principios protectorio y de primacía de la realidad.

En base a ello resulta importante diferenciar los conceptos de indicio y presunción, sin perjuicio que ambos complementen el ánimo del juez al momento de valorar la prueba.

Las presunciones son las consecuencias que el juez deduce de un hecho conocido para determinar la existencia de otro desconocido y se convierten en verdaderos elementos de prueba cuando por su número, precisión y gravedad, tienen la entidad suficiente para producir convicción conforme a la sana crítica racional. ${ }^{16}$

Es un razonamiento que, parte de un hecho determinado denominado indicio, para luego aplicar el conocimiento surgido de la experiencia común frente al orden normal de ocurrencia de las cosas, posibilitando afirmar la existencia de otro hecho que en definitiva se pretende acreditar (Devis Echandía, 1981, p.694).

Los indicios, por si solos no tiene valor probatorio alguno, tal el caso del rastro, huella, vestigio, pero sin embargo pueden tomar relevancia cuando tienen la entidad suficiente, a partir de la aplicación de una operación lógica, inferir la existencia de otro desconocido (Alsina, 1956, p. 683).

\footnotetext{
${ }^{15}$ Ley 20.744, art. 52 y Ley $N^{\circ} 27.321$ (modificación al régimen de contrato de trabajo), art. 54

${ }^{16}$ Código Procesal Civil y Comercial de la Nación (Ley N¹7.454, ref. por Ley 22.434), art. 163, inc. $5^{\circ}$.
} 
La relevancia de los indicios alcanza la jerarquía de presunción cuando se encuentren relacionados con otros elementos, siendo ilustrativo señalar por ejemplo en el caso de un siniestro laboral, el horario aproximado que el testigo vio trabajando al demandante, características del accidente en ocasión del trabajo y las herramientas que se vale el trabajador para realizar su labor profesional.

Es necesario otorgar a cada indicio la asignación correcta eficacia probatoria, de lo contrario a decisión podría adolecer de un excesivo rigorismo formal, cuando solo se pretende la verificación contundente de los hechos.

En tal sentido resulta útil considerar un conjunto de evidencias tales como las características del daño, dificultad probatoria, tiempo transcurrido, pérdida de la historia clínica, conducta omisiva del demandado en la producción probatoria. ${ }^{17}$

Sin perjuicio de la importancia asignada a las prueba de presunciones, no es posible considerarla como un parámetro de medición autónoma, ya que podría apartarse fácilmente de la realidad delos hechos, llevándonos a un estado de absoluta indefensión, supuesto en el cual podría impugnarse su misma validez constitucional por afectación al debido proceso.

\section{CARGAS DINÁMICAS PROBATORIAS Y DEBER DE COLABORACIÓN}

Esta figura procesal tiende a imponer mayores cargas probatorias a quien se encuentra en mejores situación para acreditar los hechos conducentes para la resolución del caso.

La carga de la prueba señala al obligado en acreditar un hecho determinado dentro del proceso, en tanto la distribución de la carga de la prueba o carga dinámica de la misma, pone en evidencia al sujeto procesal que se encuentra en mejores condiciones de acreditar un determinado hecho.

Si una parte sostiene que un hecho ha sucedido en contra del orden normal de las cosas, naturalmente corre con la obligación de acreditarlo de modo fehaciente, dejando de lado todo tipo de formalidades rígidas y sin sentido alguno.

Generalmente el empresario, dueño del establecimiento comercial, es quien se encuentra en inmejorables condiciones fácticas, económicas y técnicas para aportar determinados hechos a fin de crear un estado de convencimiento con respecto a la inexistencia de los hechos invocados por el trabajador, como motivo de la obligación que le asiste de llevar los libros laborales con las formalidades de ley. ${ }^{18}$

Sin embargo, por sí solos no prueban los hechos alegados por el empleador ya que son llevados de modo unilateral y sin control de parte.

\footnotetext{
${ }^{17}$ Superior Tribunal de Justicia del Chaco, Sala $1^{\circ}$ (06/06/13) "Vallejos, Heraldo c/ Pistón Carlos y Gauna Vilma s/ Sumario", Expte...ำ 455/05-2-L. Sentencia Definitiva N 177. Jueces: Toledo R. - Avalos R.. Tribunal de Origen: Cámara de Apelaciones del Trabajo de Presidencia Roque Sáenz Peña.

${ }^{18}$ Ley N²0.744, art. 52
} 
Debe desplegar una conducta capaz de demostrar un claro interés en el esclarecimiento de la verdad, aportando activa y voluntariamente los elementos necesarios para acreditar cualquier hecho derivado de la relación laboral, incluso para la demostración de un hecho insólito ocurrido bajo sus órdenes. ${ }^{19}$

La activa predisposición, merece una valoración positiva de la conducta procesal de las partes, siendo un deber que corresponde no solo al demandado sino también sobre todos los interesados en el proceso, incluso los auxiliares y aún más cuando partimos de la existencia de dificultad probatoria, de lo contrario se afecta el deber de colaboración (Vázquez Vialard, A. 1984, p. 389$){ }^{20}$

$\mathrm{Al}$ respecto se ha dicho que: "la conducta observada por las partes durante la sustanciación del proceso podrá constituir un elemento de convicción corroborado en las pruebas, para juzgar la procedencia de las respectivas pretensiones. Es que el proceder litigioso de alguna de las partes (su mendacidad, reticencia o actitud obstructiva del trámite), puede adquirir -estando reunidas determinadas circunstancias- valor probatorio" (Brain, H. 2011, p. 408).

En cuanto a las negativas infundadas, cabe indicar que el principio de autorresponsabilidad de las partes del proceso, otorga el mismo valor de convicción a las actitudes omisivas que a la misma manifestación positiva de voluntad, siendo interesante destacar que en variadas ocasiones estas cuestiones solo conducen a dilatar el desarrollo del proceso, pero naturalmente podrá responder por las sanciones que le correspondan.

\section{EL SILENCIO}

Dentro del proceso laboral, el silencio podrá ser considerado como reconocimiento de los hechos, del mismo modo que ocurre con los supuestos de respuestas evasivas o de mera negativa general de los hechos alegados en la demanda.

Es una cuestión abordada también por la nueva legislación civil y comercial, donde el silencio opuesto a una interrogación, en principio de debería ser considerado como una manifestación de voluntad, excepto los casos en que exista un deber de expedirse. ${ }^{21}$

La legislación laboral de fondo, considera al silencio del empleador como una presunción iuris tantum a favor del trabajador, entendiéndose un accionar contrario a la buena fe y un medio para evitar la incertidumbre del trabajador sobre las circunstancias de la relación laboral. ${ }^{22}$

\footnotetext{
${ }^{19}$ Cámara Nacional de Apelaciones del Trabajo, Sala 5 “ “Barrionuevo c/ La Mudadora Moderna SRL”, Sentencia N 57.790.

${ }^{20}$ Cámara de Apelaciones en lo Civil, Comercial, Laboral y de Minería de Neuquén. Autos “A.H., H. c/ P. S. N. SRL E I.P.P. S.A. y P.A. S.A. s/ Cobro de Haberes e Indemnización de Ley". Fallo Nº7150239 - Jueces: Vergara R. - De la Fuente E.. Citas: Cámara Nacional de Apelaciones en lo Comercial, Sala D (24/04/84), "P. E H., J. C. P. P. M. S.A.", La Ley 1985-A, 309.

${ }^{21}$ Ley $\mathrm{N}^{\circ} 26.994$, art. 263

${ }^{22}$ Ley $\mathrm{N}^{\circ} 20.744$, art. 57
} 
Párrafo aparte merece toda consideración relativa al silencio de trabajador, donde debemos distinguir las cuestiones relativas a circunstancias de la relación laboral, de aquellas relacionadas con las formalidades del distracto, donde no puede ser entendido en cuanto a renuncia de empleo se refiera. ${ }^{23}$

En otras palabras no es posible interpretar el silencio el trabajador como expresión de consentimiento puesto que la renuncia o la novación no se presumen.

$\mathrm{Al}$ respecto se ha entendido que el silencio del trabajador puede constituir una presunción en su contra: "pero solo en especiales situaciones, por cuanto se parte como principio de la noción que el trabajador no siempre está en posición de reclamar y salir airoso en el reconocimiento de sus derechos conservando su puesto de trabajo". ${ }^{24}$

En tal sentido se ha dicho que: "tal principio cede a la exigencia de la seguridad jurídica, por una parte, en atención a las circunstancias relativas a las personas y, por otra, cuando ha transcurrido un tiempo suficiente para entender que tal situación ha sido consentida. Por ello resulta arbitrario el pronunciamiento judicial que receptó el reclamo de diferencias salariales del actor afectado por un cambio de tareas y, sin resistirse pudiendo hacerlo, cumplió con las nuevas tareas sin formular cuestionamiento alguno". ${ }^{25}$

Ahora la situación cambian cuando nos referimos a la disolución del vínculo, teniendo presente que: "no hay norma alguna que obligue al trabajador a rechazar el despido de acuerdo o que acuerde valor a su silencio. Por el contrario, el artículo 919 del Código Civil, quita valor al silencio del trabajador y el 57 de la Ley de Contrato de Trabajo, solo acuerda valor presuncional al silencio del empleador, pero no existe ninguna disposición que ponga al dependiente frente a la carga de rechazar el despido". ${ }^{26}$ (Mark. M. 2005. p. 117).

Desde otra óptica se ha entendido que "sin perjuicio de lo que expresa el artículo 57 de la Ley de Contrato de Trabajo, en cuanto al valor presuncional del silencio, hay que integrar la norma con el artículo 919 del Código Civil y considerar que el silencio observado frente a la intimación del trabajador importa manifestación de voluntad "conforme a la interrogación" porque había "una obligación de explicarse ante la ley". ${ }^{27}$

Resulta útil señalar que el la nueva legislación civil y comercial, haciendo referencia al silencio como manifestación de voluntad y manteniendo básicamente los preceptos del anterior del Código Civil ${ }^{28}$ dice que el "opuesto a actos o a una interrogación no es considerado como una manifestación de voluntad conforme al acto o la interrogación, excepto en los casos en que haya un deber de expedirse que puede resultar de la ley, de la voluntad de las partes, de los usos y prácticas, o de una relación entre el silencio actual y las declaraciones precedentes”. ${ }^{29}$

\footnotetext{
${ }^{23}$ Ley $\mathrm{N}^{\circ} 20.744$, art. 58.

${ }^{24}$ Cámara de Apelaciones del Trabajo de Resistencia, Chaco (29/09/99) “Giménez Obdulia c/ Andrés Sosa y/u Otro y/o Quien resulte responsable s/ Diferencia de Haberes, Etc". L000 186 Rsd-75-99 S. Jueces: U. de Rajoy, Y. - Siri, E.

${ }^{25}$ Suprema Corte de Justicia de Buenos Aires, (31/06/84) "Beretta, Salvador A. c/ Drago, Beretta y Cía. S.A.", publicado en revista Derecho del Trabajo, 1984-B, 1812.

${ }^{26}$ Cámara Nacional del Trabajo, Sala $4^{\circ}$ (20/09/91) Fernández c/ Asig. SRL s/ Despido

${ }^{27}$ Cámara Nacional de Apelaciones del Trabajo, Sala $4^{\circ}$ (30/12/91) “Brandon César A. c/ Porcel, Teodoro s/ Despido.

${ }^{28}$ Código Civil (Ley N³40), art. 919

${ }^{29}$ Ley $\mathrm{N}^{\circ} 26.994$, art. 263
} 
Como se verá, la presunción legal puede activarse ante el silencio opuesto a una concreta intimación cursada por un interesado, relacionada con el cumplimiento de obligaciones derivadas del contrato de trabajo, para el caso de no efectuarse dentro de los dos días hábiles siguientes..$^{30}$

Las comunicaciones telegráficas epistolares, que las partes se hayan cursado en forma previa al inicio del proceso, tienen una clara relación con la interposición de la demanda, contestación y sus requisitos.

Es importante destacar este aspecto ya que instrumentan actos previos, que hace surgir lo que se conoce como "invariabilidad de causa", donde se determina el límite del ámbito fáctico donde se debatirán las cuestiones controvertidas en oportunidad de iniciarse el proceso.

De este modo al acotarse la facultad jurisdiccional, cobra importancia el contenido de la redacción de misivas, específicamente en cuanto a la formalización de la conclusión de la relación laboral.

Ahora bien, cuando se no se han tenido en cuenta emplazamientos postales enviados por el trabajador, y su contenido se refiere elementos conducentes para la dilucidación de la causa, el juzgador debe brindar las explicaciones de su reticencia.

Como se verá, esta cuestión no está ubicada dentro de las actividades probatorias llevadas a cabo dentro del proceso, por lo que debe ser propuesta al momento de promover o contestar la acción ${ }^{31}$, por medio del ofrecimiento de prueba documental, con correspondiente subsidiara para requerir la remisión de los originales al Correo Oficial, para el supuesto caso de ser desconocida por la parte contraria. ${ }^{32}$

Se trata de cuestiones relacionadas con el derecho de fondo, y su valoración dependerá de la existencia de diversos supuestos particulares y profundizar más el análisis de las mismas escapa a la órbita de estudio propuesto.

En efecto, la legislación adjetiva del Chaco, establece como uno de los requisitos para la contestación de la demanda, el reconocimiento o negaciones de los hechos, destacándose que el silencio podrá ser considerado en la sentencia como reconocimiento de los hechos alegados por el actor. ${ }^{33}$

En realidad, la desventaja que hace nacer el silencio es la de: "dejar librado al arbitrio del magistrado la consideración de que éstas pudieran operar como un reconocimiento implícito de la verdad de los hechos a que aquellos asertos del actor se refieran... no constituye una presunción legal de reconocimiento de los hechos, sino que significa un indicio que el Juez deberá valorar discrecionalmente" (Vitantonio, 2009, p. 365).

Como se puede apreciar, no se trata de una consecuencia automática que imponga una obligación ineludible al juez, sino por el contrario, podrá considerarlo así, en base al análisis completo e integral que efectúe de los elementos obrantes en la causa y de acuerdo a las reglas de la sana critica racional.

\footnotetext{
${ }^{30}$ Ley $\mathrm{N}^{\circ} 20.744$, art. 57

${ }^{31}$ Ley $\mathrm{N}^{\circ} 7.434$, arts. 166 inciso d) y 177 inciso e)

32 Ley $\mathrm{N}^{\circ} 7.434$, arts. 166 inciso d) y 177 inciso c)

${ }^{33}$ Ley $\mathrm{N}^{\circ} 7434$, art. 177 , incisos b) y c)
} 


\section{OBLIGACIÓN DE DECLARAR SI LOS LIBROS SON LLEVADOS EN LEGAL FORMA}

El apercibimiento previsto para su incumplimiento es la consideración de su inexistencia $^{34}$, no siendo posible exhibirlos en alguna etapa posterior del proceso, aun cuando los mismos se encuentran llevados conforme a las previsiones legales.

Si bien no representa una cuestión dificultosa, resulta útil aludirla como un aspecto particular y especialmente tratado por la legislación procesal chaqueña, destacando de modo comparativo que la vecina provincia de Corrientes, Santa Fe y la Nación, no han previsto esta cuestión para sus ordenamientos procesales. ${ }^{35}$

Por su parte la Ley de Contrato de Trabajo haciendo referencia a la omisión de la exhibición de libros, registros y planillas, hace presumir a favor de las afirmaciones del trabajador sobre las circunstancias que debía figurar en sus asientos..$^{36}$

Sin perjuicio de los diversos tratamientos procesales dados a esta cuestión, debemos tener presente que los libros y las registraciones contables, tienen como misión fundamental, la de hacer constar la nómina exacta de personal y su falta de presentación da lugar a la presunción a favor del trabajador con respecto a la fecha de inicio y fin de la relación laboral ${ }^{37}$ como también la determinación de la categoría ostentada. ${ }^{38}$

Se trata de una cuestión importante toda vez que, la omisión de llevar los libros de ley, faculta al Juez a fijar el importe del crédito laboral, para el caso que esta cuestión se encuentre controvertida, siempre que sea efectuada de modo fundado y que sus existencia sea probada por otros medios. ${ }^{39}$

\section{VALORACIÓN DE LA PRUEBA TESTIMONIAL}

Tiene una gran importancia dentro de proceso laboral, en razón de que en la mayoría de los casos planteados en sede judicial, no existe instrumentación formal del vínculo cuestionado, teniendo presente la informalidad que lo caracteriza, teniendo gran eficacia para demostrar la relación laboral, antigüedad, categoría, manera en que aconteció el distracto.

\footnotetext{
${ }^{34}$ Ley $\mathrm{N}^{\circ} 7.434$, art. 177, inc. f)

${ }^{35}$ Código de Procedimiento Laboral de la Provincia de Corrientes (Ley N 3.540), art. 41. Código de Procedimiento Laboral de la Provincia de la Provincia de Santa Fe (Ley N 7.945), art. 47. Ley de Organización y Procedimiento de la Justicia Nacional del Trabajo (Ley N¹8.345), art. 68

${ }^{36}$ Ley $\mathrm{N}^{\circ} 20744$, art. 55

${ }^{37}$ Cámara de Apelaciones del Trabajo de Resistencia, Chaco, Sala $1^{\circ}$ (14/04/93) "Acosta O. c/ Aguirre de Buyatti y otros s/ Diferencia de Haberes. Jueces: Siri - U. de Rajoy

${ }^{38}$ Cámara de Apelaciones del Trabajo de Resistencia, Chaco, Sala $1^{\circ}$ (30/11/93) "Aballay, Juan Carlos c/ Juan Cecilio Rotger s/ Laboral. Jueces: Siri - U. de Rajoy

${ }^{39}$ Corte Suprema de Justicia de la Nación (25/05/96) “Caamaño, Ernesto c/ Interior Wear SA y otro" DT 1997-A-57. Idem (09/12/93) “Miller, Beatriz c/ Briet, Joan, JA 1997-I.
} 
La acreditación de la relación laboral se puede alcanzar verificándose la concurrencia personal del actor al establecimiento comercial del demandado de modo asiduo, por la recepción de instrucciones, de acuerdo a la modalidad en la prestación del servicio, gastos y pagos convenidos, entre otros.

El testimonio debe ser merituado en relación al conjunto de la prueba rendida que resulte conducente para la resolución del caso y de acuerdo a las especiales características del caso, modalidad de la actividad, analizando su precisión y concordancia con lo expresado en el escrito de promoción ${ }^{40}$, siendo posible dejar de lado aquellas declaraciones consideradas sospechosas, interesadas, preparadas o falaces.

Resulta trascendente, considerar el engranaje de evidencias en base a la proximidad del testigo con el hecho analizado, capacidad intelectual y de razonamiento, claridad expositiva y memoria, resultando de utilidad para para acreditar relación laboral, antigüedad, categoría, manera en que ocurrió el distracto.

Si bien la declaración del testigo único resulta débil, va tomando fuerza y credibilidad en la medida que vayan coincidiendo con los demás elementos de prueba ${ }^{41}$, y así también resulta interesante destacar que no existe motivo alguno para excluir a los testigos enfrentados, puestos que los mismo no deben ser contrarrestados entre sí, ya que sus declaraciones no se cuentan sino se pesan, prestando atención a sus coincidencias y falta de contradicciones.

Los testigos que afirman en positivo, prevalecen respecto de los que declaran en negativo, pero deben ser apreciados con respecto a las restantes pruebas, teniendo presente que en principio, los testigos no mienten, siendo posible detectar cualquier mentira incurrida debido a la severidad del método empleado para la interrogación y en consecuencia requiere un mayor análisis descartarlos que aceptarlos.

En cuanto a la elaboración de los pliegos interrogatorios, la practica enseña para dar posibilidad de una mejor y más creíble declaración que no se deben efectuar preguntas de modo sugestivo, sino en primer término elaborar la pregunta de modo afirmativo y luego retirar el sujeto o bien el predicado, a fin de evitar todo tipo de planteos de nulidad que pudieran efectuarse.

En cuanto a la declaración en base a comentarios o por referencias ajenas, si bien la misma no opera como prueba directa, lo cierto es que deben ser apreciadas como elementos indiciarios junto a otras pruebas, a fin de lograr la elaboración de presunciones.

No resulta prudente excluirlos de la valoración integral, siempre que sus declaraciones aparezcan corroboradas por otros elementos de juicio que permitan alcanzar la dilucidación de la verdad real, caso contrario la lógica puede verse afectada como cuando ante situaciones de dificultades probatorias se pretendan alcanzar una verificación contundente del hecho debatido.

\footnotetext{
${ }^{40}$ Superior Tribunal del Justicia del Chaco, Sala $1^{\circ}$ (23/05/13) "Wolcoff, Jorge A. c/ Amarilla Automotores S.A. y/o Amarilla S.A. y/o Quien Resulte Responsable s/ Despido, etc.”. Expte. N 67.020, Año 2009, Sentencia Definitiva N 173, Jueces: Lucas M. Fonteina M. Tribunal de Orígen: Cámara de Apelaciones del Trabajo, Sala $2^{\circ}$.

${ }^{41}$ Cámara de Apelaciones del Trabajo, Resistencia, Chaco, Sala $2^{\circ}$ (22/03/01) "Fernández, César Manuel c/ Sindicatos de Trabajadores Viales de la Provincia del Chaco s/ Despido", Expte. N 419/00. Jueces: R. de Dib - Verón
} 
Resulta necesario efectuar el cotejo de las mismas con las características de las otras pruebas, tal el caso de la historia clínica, daño padecido, fecha, hora aproximada de ocurrencia del siniestro.

No resulta razonable pensar por ejemplo que, los mismo testigos con sus declaraciones sirvan por un lado para acreditar el vínculo laboral y por el otro para descartado para demostrar un accidente de trabajo a la luz de una supuesta falta de precisión y dejando de considerar el conjunto del plexo probatorio.

En cuanto a la confrontación de los testimonios con la exposición policial, ante un supuesto caso en que se ha disimilado un accidente doméstico a un verdadero infortunio laboral, se ha entendido que cabe partir de hechos probados tales como, por un lado: la prestación del servicio a favor del demandado en el establecimiento comercial del demandado donde el primero realizaba tareas de molienda de carne con una maquina profesional destinada a tal fin y por el otro: que un día determinado padeció un accidente en el que perdió cuatro dedos de la mano derecha, sufriendo una consecuente incapacidad total y permanente. $4^{22}$

Debe darse trascendencia a la totalidad del caudal probatorio, cuando del mismo sea posible extraer con ficción suficiente y razonable el modo y lugar de ocurrencia del hecho, más allá de las manifestaciones que puedan efectuarse ante la autoridad policial.

\section{VALORACIÓN DE LA PRUEBA PERICIAL}

La prueba de peritos ${ }^{43}$ es un medio probatorio de suma utilidad, cuando sean necesario contar con apreciaciones técnicas de expertos en determinados temas, como por ejemplo el nexo causal el accidente con el vínculo laboral, determinación de incapacidad, cuestiones indemnizatorias complejas en sus múltiples causas, no siendo prudente, en principio, apartarse de las opiniones del especialista.

El juzgador efectúa un análisis lógico de los elementos que surgen del dictamen pericial, acudiendo a las bases de conocimiento del experto, puntos sobre los cuales no le será posible manifestarse, pero cuando observa las conclusiones, lleva adelante la técnica de apreciación de la prueba de acuerdo a la sana crítica racional, campo en el cual se presume que cuenta con conocimientos adecuados.

Como una pauta razonable para separar las funciones que le corresponde a cada uno, cabe indicar que la técnica empleada por el Tribunal es la de interpretación de los hechos litigiosos, conducta desplegada por las partes y por ultimo aplicación de la norma jurídica al

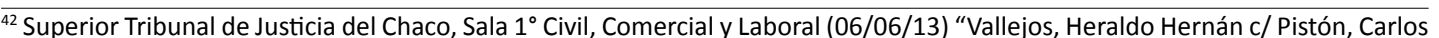
y Gauna, Vilma s/ Sumario", № 455/05-2-L. Jueces: Toledo R. - Avalos R.. Tribunal de Origen: Cámara de Apelaciones en lo Civil, Comercial y del Trabajo Sala Tercera de la ciudad de Presidencia Roque Sáenz Peña.

${ }^{43}$ Ley $\mathrm{N}^{\circ} 7.434$, art. 264.
} 
caso concreto, en tanto debemos mencionar que el perito no tiene aptitud para emitir juicios de valor en relación a las conductas ya sean valiosas.

El Código Procesal Laboral del Chaco, establece ciertas pautas de estimación tales como: la "competencia del perito, los principios científicos y técnicos en que se funda, la concordancia de su aplicación con las reglas de la sana crítica, las observaciones formuladas por los consultores técnicos o letrados, conforme las impugnaciones dadas y demás elementos de convicción que la causa ofrezca". ${ }^{44}$

Si el dictamen aparece debidamente fundado en principios técnicos, de modo coincidente con los restantes medios de prueba obrantes en las actuaciones judiciales, resulta prudente aceptar sus conclusiones, caso contrario el fallo necesariamente debe fundamentar los principios que determinaron su apartamiento.

Cabe puntualizar que: "las conclusiones del dictamen no obligan a los jueces, que son soberanos en la ponderación de la prueba, pero para prescindir de ellas se requiere cuando menos, se opongan otros elementos, no menos convincentes" (Pírolo, M, 2011, p.256).

Así por ejemplo, en orden al porcentaje de incapacidad se sostuvo que cuando alcanza a un 50 por ciento, esa cifra solamente configura un parámetro para la evaluación del daño padecido, pero no un dato insuperable y como se puede apreciar, el Juez siempre puede apartarse de los motivos del dictamen aun cuando sean en sentido asertivo, siempre que se exprese los fundamentos de su convicción contraria.

\section{VALORACIÓN DE LA PRUEBA CONFESIONAL}

Mucho se ha hablado con respecto a su eficacia procesal, tal es así que algunas legislaciones adjetivas como la del Chaco ha dispuesto su reciente eliminación, en el entendimiento que se ha vuelto una medio vetusto, representando un ritual que especula con el nerviosismo, el grado de preparación cultural y la mayor o menor fortuna del absolvente, señalándose que las posiciones serán siempre negativas.

Resulta interesante señalar la importancia que tenía para la suerte del proceso la declaración ficta, aspecto que mejoraba considerablemente la posición del trabajador en el proceso, donde de modo anticipado y sin necesidad de esperar el dictado de la sentencia definitiva podría tener por reconocido un crédito líquido y comenzar el curso de una ejecución por vía de incidente.

En cuanto a su eficacia probatoria se ha entendido que no depende su confirmación de otros elementos probatorios y para ser contrarrestado debe existir producción de prueba en contrario, incluso en algunos supuestos se ha aceptado la declaración de personas que no se

${ }^{44}$ Ley $\mathrm{N}^{\circ} 7434$, art. 272 
referían a hechos personales, tal el caso de representantes de personas jurídicas, ya que por su condición puede encontrarse en condiciones de conocer cuestiones de hecho relevantes para la causa.

Así también debemos tener presente que cuando dos afirmaciones o negaciones de las partes coinciden, excluyen el hecho de la prueba, dándose por válido al mismo, salvo que se encuentre comprometido el orden público, aspectos que ponen en evidencia su trascendencia dentro del proceso laboral.

\section{CONCLUSIONES}

La valoración de la prueba es una cuestión privativa de los jueces de grado, quienes deben considerar los elementos de prueba de modo integral y en conjunto, dentro del contexto propuesto por los interesados del proceso, sin que sea necesario requerir un detallado relato de los hechos.

En todo proceso laboral, una vez demostrada la relación laboral, se activa la presunción legal sobre la existencia de un contrato de trabajo, conforme lo normado por la legislación laboral de fondo ${ }^{45}$, jerarquizando la situación procesal del trabajador.

Hasta aquí no se presentaría inconveniente alguno, pero sin embargo cuando se intenta acreditar otras cuestiones tales como la mecánica de un siniestro laboral, causa de una enfermedad profesional, antigüedad, categoría e incluso la manera en que habría ocurrido el distracto, entre otras cuestiones, donde existe orfandad probatoria, comúnmente debido a la falta de testigos presenciales.

Resulta entonces necesario indagar la realidad de un modo diferente e indirecto, acudiendo prudentemente a las presunciones judiciales que son las establecidas por el Juez mediante "el examen de los indicios, según su ciencia y conciencia, sin sujeción a ningún criterio legal. Estas harán plena prueba cuando fueren graves, precisas y concordantes y tuvieren conexión con el hecho que se trata de averiguar" (Brain, 2008, pág. 409).

En tal sentido, es necesario lograr un engranaje entre las distintas evidencias, por medio de la conjunción de indicios que permitan conducir a la existencia de presunciones para lograr la elaboración de un juicio adecuado en relación al grado de responsabilidad que le puede corresponder a cada sujeto.

No resulta necesaria alcanzar un nivel de certeza compatible con la verdad absoluta sino solamente moral, en otras palabras, basta un alto grado de probabilidad de la existencia del suceso.

Todo ello con la finalidad de efectuar una interpretación completa e integral de los elementos traídos a juicio, integrados y armonizados, alcanzando una derivación razonada del derecho vigente.

${ }^{45}$ Ley $\mathrm{N}^{\circ} 20.744$, art. 23 
$\mathrm{Al}$ respecto se ha entendido que: "si media un evidente apartamiento de los hechos, del buen sentido o reglas de la sana crítica, la sentencia es arbitraria, como si abandona el correcto entendimiento judicial del material probatorio y le da un tratamiento no adecuado" (Sagues, 2002, p. 271).

Por último, ha sido intención de este trabajo brindar una serie de aportes novedosos y útiles relacionados con la valoración de la prueba, evitando caer en consideraciones dogmáticas y preservar el principio de la verdad real.

\section{REFERENCIAS BIBLIOGRÁFICAS}

Alsina, H. Tratado Teórico Práctico de Derecho Procesal Civil y Comercial. Tomo III, $2^{\circ}$ Edición Editorial Ediar, Buenos Aires, 1956.

Brain, Horacio Daniel. Derecho Procesal del Trabajo. Editorial. Advocatus, Córdoba, 2008

Devis Echandía, H. Teoría General de la Prueba Judicial, Tomo II, pág. 694, 2 Edición. Editorial Zabalía, Buenos Aires, 1981.

Ensink, J. Ley de Contrato de Trabajo y su Reforma Anotada. Editorial Víctor P. Zabalía, Buenos Aires, 1976.

Mark. Mariano. Ley de Contrato de Trabajo. Legislación Complementaria. Lexis Nexis. Buenos Aires, 2005.

Morello A., Sosa G., Berizonce R., Códigos Procesales en lo Civil y Comercial de la Provincia de Buenos Aires y de la Nación, Comentados y Anotados, Editorial Platense. Abeledo - Perrot, Buenos Aires, 2005, Tomo V-A.

Pírolo, Miguel Ángel; Murray, Cecilia M.; Otero, Ana María. Manual de Derecho Procesal del Trabajo. Actuación ante la Justicia Nacional y Federal. $3^{\circ}$ Edición actualizada y ampliada. Editorial Astrea. Buenos Aires. 2011.

Sagués Néstor. Recurso Extraordinario, Editorial Astrea Buenos Aires 2002.

Vázquez Vialard, Antonio, Tratado de Derecho del Trabajo. Editorial Astrea, Buenos Aires 1985, Tomo III. 
Vitantonio, Nicolás. Director. Eguren, María Carolina - Coordinadora. Código Procesal Laboral de la Provincia de Santa Fe. Comentado. Concordado con el CPL de Corrientes. Tomo I, arts. 1 a $57.1^{\circ}$ Reimpresión. Nova Tesis Editorial Jurídica, Rosario, 2009.

\section{CURRICULUM VITAE}

\section{Jorge Gustavo Dahlgren}

Abogado. Especialista en Derecho Procesal. Especialista en Seguridad Social. Especialista en Derecho Laboral. Doctor en Derecho Público, Política y Gobierno. Profesor Adjunto por Concurso de Derecho Administrativo y Procesal Laboral (UNNE). Docente Investigador. Categoría V. Ministerio de Educación de la Nación. Integrante de la Comisión Reformadora del Código Procesal Laboral del Chaco. Agente Fiscal No 12 - Fuero Civil, Comercial y Laboral (Cargo actual). Juez Subrogante del Tribunal Electoral - Chaco (Período 2010 a 2012 y 2014 a 2016). Miembro Titular en Comisiones Examinadoras en Concurso de Cargos (Consejo de la Magistratura).

dahlgrengustavo@arnet.com.ar 